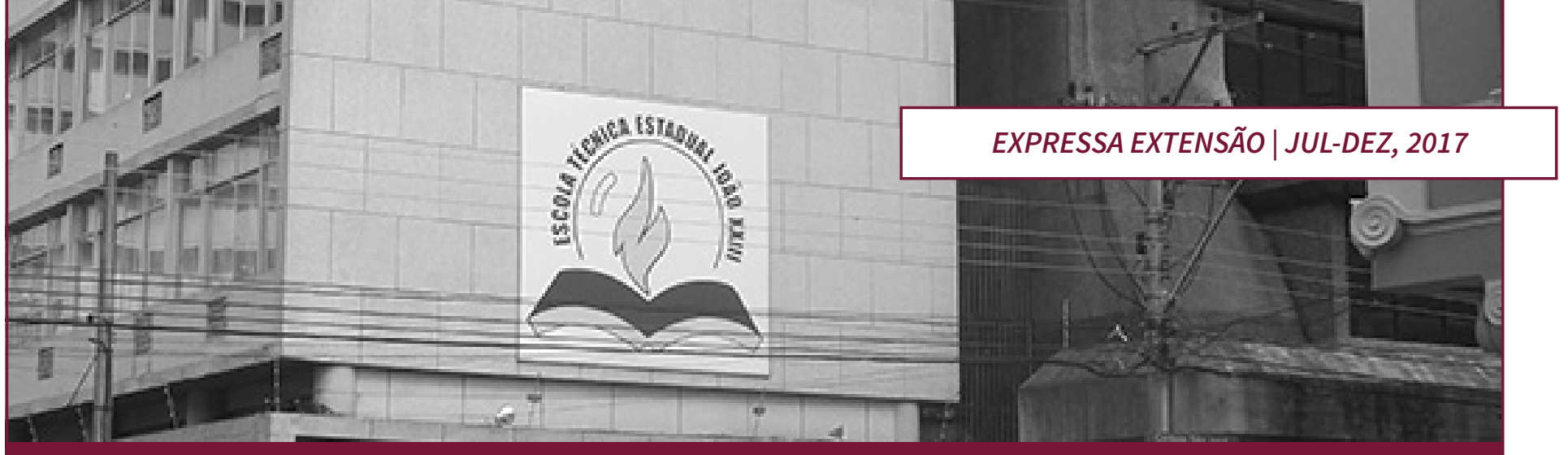

\title{
EXPERIMENTOS EM AULA: UM EXERCICIO INTERDISCIPLINAR DE ENSINO
}

EXPERIMENTS IN CLASSROOM: AN INTERDISCIPLINARY EXERCISE OF TEACHING

Luis Goulart Campello ${ }^{1}$ Cynthia Farina²

Este texto traz a discussão uma investigação realizada no Mestrado Profissional em Educação e Tecnologia - MPET do Instituto Federal de Educação, Ciência e Tecnologia Sul-Rio-Grandense - IFSUL campus Pelotas, RS nos anos de 2015-16, a pesquisa se assume a partir de observações realizadas com um grupo de estudantes do quinto ano do ensino fundamental de uma Escola Técnica Estadual no bairro Fragata, nesta cidade, onde a criação manuscrita de textos epistolares surge como uma prática interdisciplinar potente de ensino, com a intenção de amenizar as dificuldades de aprendizagem deste grupo. Ao passo que as atividades se desenvolviam se percebeu a necessidade de pensar as condições funcionais de tal prática, e ir além. Além de somente pensar tal atividade como redentora de dificuldades de aprendizagem, mas como processo de formação mais amplo anunciando um diálogo que perpassa a escrita de si no contexto de um processo de formação, compreendendo a escrita como uma prática capaz de reinvenção de modos de pensar e ser, a qual nos faz refletir sobre os encontros que nos atravessam em procedimentos de formarmos, discentes e docentes. $O$ método de pesquisa apresentado é o cartográfico. A cartografia cria oscilações próprias, descaminhos que surgem conforme as pistas dos trajetos vão se desvelando no tecer, tramar conceitualmente uma discussão unindo a experiência a problematização.

Palavras-chave: Cartas epistolares. Experiência. Cartografia.

${ }^{1}$ Ronaldo Luis Goulart Campello - Mestre em Educação pelo Instituto Federal de Educação, Ciência e Tecnologia Sul-Rio-Grandense - IFSUL, Pelotas, RS. E-mail: ronaldo.campello@hotmail.com; ${ }^{2}$ Cynthia Farina - Doutora em Educação, coordenadora do GP Educação e Contemporaneidade: Experimentações com Arte e Filosofia (Experimenta); professora do Programa em Pós-graduação em Educação do Instituto Federal de Educação, Ciência e Tecnologia Sul-rio-grandense - IFSUL, Pelotas RS. E-mail: cynthiafarina@pelotas.ifsul.edu.br 


\section{ABSTRACT}

This text brings the discussion an investigation carried out in the Professional Masters in Education and Technology - MPET of the Federal Institute of Education, Science and Technology Sul-Rio-Grandense - IFSUL campus Pelotas, RS in the years 2015-16, the research assumes from a fifth year of elementary school students at a State Technical School in the Fragata neighborhood, in the city where the manuscript creation of epistolary texts emerges as a powerful interdisciplinary teaching practice, with the intention of alleviating the difficulties of Learning process of this group. As activities developed, they realized the need to think about the functional conditions of such a practice, and to go further. In addition to thinking of such activity as a redeemer of learning difficulties, but as a process of broader formation announcing a dialogue that permeates writing itself in the context of a formation process, understanding writing as a practice capable of reinventing ways of thinking And being, which makes us reflect on the encounters that cross us in procedures of training, students and teachers. The research method presented is cartographic. The cartography creates its own oscillations, misalignments that arise as the tracks of the paths are unveiled in the weave, conceptually plot a discussion linking the experience to the problematization.

Keywords: Letter letters. Experience. Cartography.

\section{INTRODUÇÃO}

Ao pensar a composição deste texto, trago inquietações sobre encontros pertinentes à escrita. Ato/tarefa que sempre se revela arriscada. Iniciá-la é talvez a parte mais complicada do processo, organizar o caos do pensamento, encontrar as primeiras palavras, formar as primeiras frases, arranjá-las nas classes que regem as normas, conjunções conectando orações, artigos definindo ou não substantivos. Pares em um sistema alfabético/gramatical que se digladiam com as ideias. Ruminá-las, aceitá-las, dar-lhes luz. Carne ao verbo. Permitir que encontrem som na voz, na palavra úmida que deixa prenhe os pulmões, que faz corpo e se faz sentir, cria oscilações, cria o pensar.

Escrever acontece de encontros que se tecem com a leitura, de encontros com outros corpos, orgânicos ou não, com nós mesmos. Escrever parece simples, mas, não é. É um esforço colossal. Escrever possui afinidade/parentesco/semeLhança, um avizinhar-se com oscilações, movimentos de ondas, sopros de ar. É como areia no deserto bailando/perseguindo o vento. É como algo que ainda não se concluiu. Desejos de tecer textos; tramar, transformar pensamento e ideia em palavra, dar corpo ao que é incorpóreo, corporificar o que faz furos na pele, desacomoda, desestabiliza. Escrever é encontro, é devir, sempre por se fazer (DELEU- 
$Z E, 1995)$. Escrever é desconstrução que ocorre de maneira singular, construção que se faz de forma sutil, nos reconstruindo com experiências. É movimento que revela pistas, deixa rastros/pegadas pelos quais se esgueiram desejos. Escrever é criar, ligar pontos(as), pedaços, platôs onde flanamos/resistimos. O pensar é questão intrínseca/encrunhada no ato de se produzir a escrita. "Pensar [...] é um ato perigoso" (DELEUZE; GUATTARI, 1992, p. 58-59), por isso é tão difícil escrever. Não se exercita pensamento. Pensar cria movimentos, oscilações, quedas, fraturas... Pensar dói.

\section{NARRATIVAS DE UM PROFESSOR-PESQUISADOR}

Enquanto músico, fins da década de '90, me dedico à escrita, com vigor e potência a escrita de cartas pessoais. Tal ação se sustentou quase que diariamente por mais de cinco anos. O que se iniciou para divulgar um trabalho artístico-musical tomou outro corpo/forma, descobria-me na escrita, minha e de outros. Escrevia ao outro, mas antes a mim. "A correspondência é também um exercício pessoal, ao escrever lemos o que escrevemos, [...] é uma maneira de se manifestar para si e para o outro", (ORRÚ; ANDRADE, 2009, p. 04). Alguém um dia disse que a escrita é uma fala de si. Um abrir-se. Que é fácil falar/escrever de coisas de seu dia a dia, e isso se intensifica na escrita de cartas pessoais; "a correspondência é um texto por definição destinado ao outro que ajuda o individuo a aperfeiçoar-se, estimulando destinatário e remetente a avaliarem cuidadosamente os fenômenos que acontecem em seus cotidianos" (IONTA, 2011, p. 84).

Esse aperfeiçoamento tem menos a ver com uma progressão, que com perfazimentos e desprendimentos de si. De nada serve escrever se esta escrita não fortalece a desconstrução para uma nova construção, de nada serve se ela não desterritorializa. "Pensar é desterritorializar. Isto quer dizer que o pensamento só é possível na criação e para se criar algo novo, é necessário romper com o território existente, criando outro" (HAESBAERT et al., 2015, p. 09). Há de existir uma escrita que se afete por aquilo que nos passa, por aquilo que a própria escrita proporciona. A desterritorialização a partir do pensamento cartográfico consiste, segundo lanni (1996, p. 169) em "[...] o sujeito do conhecimento não permanecer no mesmo lugar, deixando que seu olhar flutue por muitos lugares, próximos e remotos, presentes e pretéritos, reais e imaginários". É necessário um novo observar, um olhar forasteiro sobre o objeto observado, mesmo que isso não seja fácil de produzir, mesmo que o objeto sejamos nós.

\section{UMA ESCRITA PERMEADA PELA TECNOLOGIA}

Estamos imersos em uma sociedade conectada, globalizada, mais intensidade desde o inicio do século XXI, fins da década de '90, onde surge uma maior 
inserção e propagação do uso dos meios de comunicação, dos quais, gradativamente passamos a utilizar. Aos poucos, fomos imergindo neste novo modelo de interação, procurando sempre algo mais, sem saber ao certo o que estávamos fazendo...

O homem como ser social sempre soube se adequar a evolução, que vai ditando os costumes, as modas, as regras que são sempre novas a todo instante. Hoje, a partir dos incrementos dos meios de comunicação abusamos demasiadamente, do uso das tecnologias, e principalmente dos recursos de interação on-line, essencial ao nosso dia a dia. Parece impossível pensar em alguém que não tenha telefone celular, e-mail, facebook, whatsapp, MSN ou outro tipo de modo de comunicação que não esteja inserido nestes 'avanços' tecnológicos.

Tais meios de comunicação proporcionam transformações que pulsam intensamente sobre questões de comunicação/interação nunca antes experimentadas pelas sociedades anteriores. "Mantendo as diferenças podemos dizer que assim como a criação da máquina a vapor, incremento tecnológico inicial e recurso que possibilitou a Revolução Industrial, têm-se nos recursos tecnológicos e nos meios de telecomunicação uma nova revolução" (CASTELLS, 1999), que possibilita ao homem de hoje interagir com seus pares da forma intensa como interage. Sua "extensão atual do desejo de relatar - de modo constante e voluntário. Tudo isso realizado a toda hora por milhões de pessoas, ás quais não incomoda o fato de estarem sempre localizáveis e disponíveis para contato" (SIBILIA, 2012, p. 175). Ao que parece, há uma vontade de comunicar-se, comunicar algo. Informar. Estar informado. Mas, não obstante é preciso que repensemos nosso modo de estar em sociedade. É preciso refletir sobre questões político-conceituais, estéticas e filosóficas que nascem sob a égide capitalista vigente.

O clique. Uma. Duas. Três vezes, e assim sucessivamente. Uma. Duas. Três ou mais horas sob a luz intensa do monitor. Frenética ou calmamente. Algo quase que instantâneo. Temos em nossa frente o simples comando 'enviar', 'minimizar', 'fechar'. 'Salvar'; 'não salvar', 'cancelar'. Janela a janela, mundos se fecham, portas se abrem, possibilidades surgem. Textos se vão, se esvaem. Navegam na rede, no emaranhado de outros tantos. Surfam na onda, que se avoluma a cada instante. Tsunami de informações. "Esta é a era da informação. A época das opiniões sobre tudo, mesmo que sejam vazias. Esta é a época em que todos opinam sobre tudo" (LARROSA, 2002). Futebol, política, religião, sexo, violência, e... e... e... existe um oceano de possibilidades entre esta "conjunção que possibilita se propagar entre, por dentro, recostando-se nas laterais, rasgando-se por meio dos verbos e atravessando-os ao meio. Formando rizomas" (DELEUZE, 1995). Não se sabe onde tem o inicio, o meio, ou o fim. Todos surgem em uma grande confusão. Mas estão ali, construindo-se; reconstituindo-se, produzindo algo novo, a partir de algo que já foi que existiu, e esta em vias de se refazer. Quase que no mesmo instante, em 
que derramamos um texto, seja via e-mail, e/ou sites sociais este texto se comunica com seu receptor intencional ou não, quase que instantaneamente. Dependendo do veículo que é utilizado às respostas são imediatas.

Mas, nem sempre foi assim, desde tempos imemoriais temos na escrita um modo de nos relacionarmos com nossos pares, inclusive com aqueles que estão longe. Esta pesquisa trata sobre uma prática de escrita muito antiga, que nos dias atuais é percebida com muito saudosismo. Pouco experimentada nesta geração das janelas, das imagens rápidas e cliques alucinados. Importantíssimo meio de comunicação/interlocução que perde sua força de potência em pouco de mais três décadas em virtude da grande expansão/evolução das tecnologias de informação que oxigena seus pulmões na rede WEB; constituindo-se assim na invenção e incremento de inúmeros modos de emissão e exibição de informações. As vantagens práticas do envio de textos, através dos correios eletrônicos onde se pode anexar arquivos e também colocar imagens; dados, faz com que este seja sinônimo de benefícios quando é utilizado, tanto por pessoas físicas quanto por empresas públicas, privadas, entre outras. Jazemos na era da informação. "A informação não deixa lugar para a experiência, a informação não faz outra coisa que não cancelar nossas possibilidades de experiência" (LARROSA, 2002, p. 24). A experiência é a forma como o conhecimento transforma o homem e as sociedades. "O sujeito da experiência seria algo como um território de passagem, algo como uma superfície sensível que aquilo que acontece afeta de algum modo, produz alguns afetos, inscreve algumas marcas, deixa alguns vestígios, alguns efeitos" (LARROSA, 2002, p. 21). Experiências reais as quais Larrosa traz em alguns de seus textos e que nos diz que são estas experiências reais que nos passam que nos acontece, nos toca. (2002a). O sujeito da experiência é um sujeito exposto. É o que se sabe, e não pura opinião.

É necessário que a experiência passe por mim, me atravesse se contextualize na realidade em que se está inserido, aquilo que foi dito, experimentado, e como nos foi dito, como foi experimentado produza sentido em mim. Se for informação advinda da fala de outros, sem existir a experienciação na realidade daquele que apreende, consiste somente de informação. Não é minha experiência. Minha prática. "Traduzir em palavras nossas próprias experiências com a arte, a política e a educação, para que cada um que as escuta com atenção contraste essas experiências com suas próprias experiências³" (LARROSA, 2015).

\section{EXPERIÊNCIAS DE AULA: ENCONTROS A PARTIR DE UMA PRÁTICA IN- TER-DISCIPLINAR DE ENSINO}

A atividade de ensino começada no ano de 2014, desencadeada por um agenciamento de experiências e um acontecimento de sala de aula, tornada

${ }^{3}$ Disponível em: <http://www.bienal.org.br/FBSP/pt/Noticias/Paginas/Conversa-com-Jorge-Larrosa.aspx>. Acesso em: 15 maio 2015. 
projeto de extensão no mesmo ano, chamada de: "As cartas que escrevo. Correspondências físicas na era digital, uma metodologia interdisciplinar de ensino e aprendizagem", ganha força em 2015 enquanto pesquisa, e toma outro nome ao ser pensada/investigada no Mestrado Profissional em Educação e Tecnologia - MPET, do Programa de Pós-graduação em Educação do Instituto Federal de Educação, Ciência e Tecnologia - IFSUL campus Pelotas; "Cartas para ler e escrever: Cartografando uma prática de ensino"; e a partir de minha docência em uma Escola Técnica Estadual no bairro Fragata na cidade de Pelotas - RS, ganha vida, corpo e formas. Tal pesquisa cartografa a troca de cartas entre estudantes, a partir de práticas interdisciplinares de escrita e leitura desenvolvidas com um grupo de alunos de um quinto ano do ensino fundamental da referida escola, com outros estudantes também de um quinto ano de uma escola rural no interior do município de Piratini - RS. O material cartografado é a correspondência trocada que ocorreu ao longo de 2015, entre ambos.

\section{A CARTOGRAFIA COMO MÉTODO DE PESQUISA}

Ao fundamentar as atividades do projeto realizado na referida escola, a partir do ponto de vista de uma pesquisa qualitativa, a qual visa focar as peculiaridades e especificidades dos grupos sociais envolvidos, e tem a finalidade de apreender os fenômenos que com este grupo ocorrem, bem como de conhecer de forma mais substancial suas vivências e as formas como se representam, e também como se interpretam em suas práticas, alia-se a tal metodologia o método cartográfico que se aproxima de algumas investigações qualitativas, e, por conseguinte se distância de outras. Segundo César et al., (2013, p. 358) isso ocorre quando, "nessas investigações, privilegia-se o estudo dos fenômenos - valores, crenças, opiniões, hábitos - separados de sua dimensão processual de produção". O processo de aproximação se dá na harmonia do compartilhamento e da produção das inquietações e das hipóteses que surgem e se insinuam na metodologia de pesquisa adotada.

O método cartográfico segundo César et al., (2013, p. 359) "não se define por suas metas traçadas anteriormente, tampouco se delimita a partir desta ou daquela ferramenta de pesquisa, embora o pesquisador não parta do ponto zero, mas se constrói a partir de um patrimônio, de uma história, de outras experienciações". Segundo Ferigato et al., a "investigação qualitativa é, portanto, uma atividade que se afirma a partir do contexto situacional, da localização e implicação do observador em relação ao objeto e seu entorno" (2011, p. 665).

A proposta cartográfica de investigação não prestigia os fins em si, mas os meios, os fazeres que ocorrem por 'entre', e não a conclusão. Aliado a prática de escrita de cartas pessoais que permite/possibilita trabalhar de um modo, onde o que interessa são os movimentos de construção das atividades escritas, posteriores leituras, das discussões, dos fatos de sua vida, seus apontamentos, seus 
conhecimentos permitindo desta forma, que cada um dos envolvidos se constitua a si mesmo, dando voz à suas palavras. A escrita autobiográfica aliada ao método cartográfico de pesquisa provoca a construção de um olhar, uma narrativa sobre suas vidas, sobre si. Prado Filho et al., $(2013$, p. 46) nos diz que a cartografia "não se refere a método como proposição de regras, procedimentos de pesquisa, mas, sim, como estratégia de análise crítica e ação política, olhar crítico que acompanha e descreve relações, trajetórias, formações rizomáticas, apontando linhas de fuga, ruptura e resistência".

Ao longo do processo de confecção deste trabalho, realizado a luz da proposta de uma metodologia de pesquisa qualitativa atravessada/abocanhada pela cartografia proposta por Deleuze e Guattari. A opção de escolher a referida turma e escola se da pelo fato de ali ser o ambiente onde as inquietações deste docente que perscruta sua professoralidade são maiores. Neste local me pus (ponho) em xeque em relação a meu exercício docente, minhas práticas, meu modo de pensar educação. Portanto, penso sobre formação quando me ponho a escrever sobre tal processo e os atravessamentos que foram produzidos em mim a partir da execução desta prática que tomo como ensino, escrita de cartas.

A cartografia, método de pesquisa proposto por Deleuze e Guattari se faz de rastros, movimentos, amplitudes e alterações, encontros, que mostram as lutas que ocorrem e me põem a pensar, que surgem e se intensificaram no decorrer da escrita. Um movimentar-se, ou estar em movimento, a partir do pensar cotidiano e seus modos de se produzir no/com/ele. O cotidiano em jogo na docência, a docência como jogo do cotidiano.

E se nos pusermos a pensar em educar como um cão que cava seu buraco, um rato que faz sua toca? No deserto de nossas escolas, na solidão sem fim, - mas superpovoada - de nossas salas de aula não seremos, cada um de nós, cães e ratos cavando nossos buracos? (GALLO, 2002, p.169).

E se produzirmos aqui, e desta forma, um modo de 'militância', de resistência ao modo dominante de lecionar? E se não se trata apenas de escavar o presente com uma mera proposta de escrita e leitura?

Desta forma abri caminhos novos, tocas por onde me esgueiro em minhas práticas professorais, em minha pesquisa, e, em meus modos de ser. Trilhar estes caminhos produz tombos provenientes dos deslizes, assim como dos saltos derivados dos encontros, conversas. Aprendizagens. O olhar tão acostumado à mesma paisagem docente agora a observa com outros olhos e da um novo sentido ao que vê, pois constitui outro território perceptivo, a partir desta escrita-pesquisa que ainda se faz. Escrever é um esforço colossal, mas é preciso singrar os céus, sentar na vassoura da bruxa e perseguir o vento, pois penso sobre formação 
quando escrevo sobre tal processo, sobre os encontros e os atravessamentos produzidos em mim, a partir da execução da escrita de cartas, por exemplo.

Pensando com Larrosa (2015, p. 52) sobre o processo de formação, “é justamente uma viagem no não planejado e não traçado antecipadamente, uma viagem aberta em que pode acontecer qualquer coisa, e na qual não se sabe onde se vai chegar". A formação aqui é pensada como viagem, ou "viagem de formação" (idem) em que se pretende um olhar para si através da palavra, através da escrita, da escrita epistolar que nos faz experimentar o mundo que nos cerca, apresentando paisagens novas a cada nova carta que chega ou vai, "assim, a viagem exterior se enlaça com a viagem interior, com a própria formação da consciência, da sensibilidade e do caráter do viajante" (LARROSA, 2015, p. 53), produzindo um diálogo que perpassa o contexto de um processo de formação, compreendendo a escrita como uma prática capaz de reinvenção de modos de pensar e ser, a qual nos faz ponderar sobre os encontros que nos atravessam em procedimentos de formação. Ao outro se escreve com o desejo de se dizer, encontrar-se através dele. A partir da escrita, escreve-se para si, "trata-se, não de perseguir o indizível, não de revelar o que está oculto, mas, pelo contrário, de captar o já dito; reunir aquilo que se pôde ouvir ou ler, e isto com uma finalidade que não é nada menos que a constituição de si" (FOUCAULT, 1992, p. 131).

Assim como quando o pássaro que alça vôo e toma distância e observa, e/ou como quando pousa em distinta a paisagem carece ser ou agir o professor-pesquisador que repensa suas práticas. Carece tomar distância e pousar os olhos sobre seus modos de ser, sobre seu corpo didático, corpo estudantil, sua professoralidade, e olhar de outro lugar suas práticas cotidianas, seu fazer pedagógico. Seu corpo-campo de pesquisa é a sala de aula, seus estudantes, a si mesmo, territórios férteis por onde se promovem agenciamentos diários. É no encontro do rio com a roda d'água, com suas aletas de madeira, que faz a mó girar e o moinho produzir, transformar o grão em farinha, é no encontro do desejo com a escrita, e da escrita com a expressão, que a palavra se faz. Flanar-cartografar sua experiência, só isso já é muito. Agenciamentos formam territórios, "o território pode se desterritorializar, isto é, abrir-se, engajar-se em linhas de fuga e até sair do seu curso e se destruir" (GUATTARI; ROLNIK, 1996, p. 323). Mas ele reconstrói-se novamente, desta vez em algo novo, que produz o novo, o ainda não experienciado, que pode desencadear novas linhas de fuga. "Estas não consistem nunca em fugir do mundo, mas antes em fazê-lo fugir, como se estoura um cano" (DELEUZE; GUATTARI, 1996, p. 72), deslizar entre essas ideias, cartografar-flanar, seguir uma linha de fuga, deambular por entre caminhos de leitura e escrita que podem gerar encontros, proporcionar ideias, assim constituindo uma trajetória de pesquisa. Aquele que perambula por entre as linhas das palavras criadas nos textos, e as linhas de fuga que escapam do 'entre', está à espreita e pode ser capturado por um encontro em dado momento. "Alguém à espreita é alguém aberto 
à turbulência do 'fora', se dispõe às afetações, atento ao inesperado. A qualquer momento alguma coisa pode acontecer; e não se sabe o quê" (VASCONCELOS, 2007, p. 01). Estar à espreita envolve o mover-se em meio a..., dentro de..., envolve o risco de criar e criar-se, ser tocado por..., tocar em...

É observar com olhar aguçado, perceber o mínimo que não se mostra, é entregar-se a paisagem e compor com ela, desconstruir e fazer-se nela.

\section{ARREMATES DESTA ESCRITA}

O que se propõe ao tecer a escrita destas palavras é trazer um diálogo que surge a partir de inquietações sobre o ato da escrita, sobre as provocações que surgem e que fazem este professor-cartógrafo, o professor-pesquisador, que é andarilho e esta sempre a espreita, desejoso de linhas de fuga, sempre transitando em vias que surgem em meio ao processo de pesquisa cartográfico, de seu fazer docente, a partir de um projeto de pesquisa que realiza no âmbito de sala de aula e que ganha/rompe fronteiras a partir de encontros que se fazem na vida deste que escreve e que reverberam possibilidades de criação.

A escrita é ato/tarefa que sempre se revela arriscada que faz corpo e se faz sentir, cria oscilações, cria o pensar. Escrever é um ato perigoso, pois criar é arriscado, e o que menos se faz nos espaços de sala de aula é tornar este espaço um espaço de criação.

\section{REFERÊNCIAS}

CASTELLS, Manuel. A sociedade em rede: a era da informação: economia, sociedade e cultura. São Paulo: Paz e Terra, 1999.

CÉSAR, Janaína Mariano; SILVA, Fabio Herbert da; BICALHA, Pedro Paulo Gastalho de. O lugar do quantitativo na pesquisa cartográfica. Fractal Revista de Psicologia, v. 25 , n. 2, p. 357-372, maio/ago. 2013. Disponível em: <http://www.scielo. br/scielo.php?pid=S1984-02922013000200009\&script=sci_arttext>. Acesso em: 17 maio 2015.

DELEUZE, Gilles; GUATTARI, Félix. O que é a filosofia? Rio de janeiro: Ed. 34, 1992. Mil platôs: capitalismo e esquizofrenia. Rio de Janeiro: Ed. 34, 1995.

Abecedário de Gilles Deleuze. In: PARNET, A. V. Produzido e realizado: 
Pierre-André Boutang, Éditions Montparnasse, Paris, 1996. Disponível em: <http:// www.docspt.com/index.php?topic=16463.0 >. Acesso em: 12 nov. 2015.

FERIGATO, Sabrina Helena; CARVALHO, Sérgio Resende. Pesquisa qualitativa, cartografia e saúde: conexões. Interface - Comunic., Saúde, Educ., v. 15, n. 38, p. 663-675, jul./set. 2011. Disponível em: <http://www.scielo.br/pdf/icse/v15n38/ aop3411.pdf>. Acesso em 17 jun. 2015.

FOUCAULT, Michel. A escrita de si. In: O que é um autor? Lisboa: Vega. 1992. p. 129-160.

GALLO, Sílvio. Em torno de uma educação menor. In: Dossiê Gilles Deleuze. Educação e Realidade, Porto Alegre, v. 27, n. 2, p. 169-178, jul./dez. 2002. Disponível em: <https://disciplinas.stoa.usp.br/pluginfile.php/16652/mod_resource/content/1/Gallo_Em_torno_de_uma_educacao_menor.pdf>. Acesso em: 5 set. 2016.

GUATTARI, F.; ROLNIK, S. Micropolítica: cartografia do desejo. 4. ed. Petrópolis: Vozes, 1996.

HAESBAERT, Rogério; BRUCE, Glauco. A desterritorialização na obra de Deleuze e Guattari. Niterói: GEOgraphia, 2002.

IANNI, Otávio. Teorias da globalização. 3. ed. Rio de Janeiro,Civilização Brasileira, 1996.

IONTA, Mariza. A escrita de si como prática de uma literatura menor: cartas de Anita Malfatti a Mário de Andrade. Rev. Estud. Fem., Florianópolis, v. 19, n. 1, jan./ abr. 2011. Disponível em: <http://www.scielo.br/scielo.php?script=sci_arttext\&pi$\mathrm{d}=$ S0104-026X2011000100007>. Acesso em: 19 jun. 2015.

LARROSA, Jorge Bondía. Notas sobre a experiência e o saber de experiência. Revista Brasileira de Educação. n. 19, p. 20-28, jan./abr. 2002. Disponível em: <http:// www.scielo.br/pdf/rbedu/n19/n19a02.pdf>. Acesso em: 15 maio 2015.

Pedagogia profana: danças, piruetas e mascaradas. 5. ed. Belo Horizonte: Auteêtica, 2015.

ORRÚ, Carla Maria dos Santos Ferraz; ANDRADE, Marieta Benedita de Paula. In: $15^{\circ}$ SEMINÁRIO DE PESQUISAS EM LINGUÍSTICA APLICADA, 15., 2009, . A escrita de si e o caráter revelador da escrita em textos não verbais. Anais... Disponível em: <http://site.unitau.br/scripts/prppg/la/5sepla/site/comunicacoes_orais/artigocarla_maria_marieta_benedita.pdf>. Acesso em: 22 set. 2015.

POE, Edgar Allan. O corvo. [S. L.]: Dark Side, 2013. 
. O homem da multidão. Máquina do Mundo Revista de Poesia, v. 2, n. 12, fev. 2005. Disponível em: <http://www.bestiario.com.br/12.html>. Acesso em: 24 ago. 2016.

PRADO FILHO, Kleber; TETI, Marcela Montalvão. A cartografia como método para as ciências humanas e sociais. Barbarói, Santa Cruz do Sul, n. 38, p. 45-59, jan./jun. 2013.

SIBILIA, Paula. Redes e paredes: a escola em tempos de dispersão. Rio de Janeiro: Contraponto, 2002.

VASCONCELOS, Maria Helena Falcão de. A escrita nômade de Clarice Lispector. Alegrar, n. 4, 2007. Disponível em: <http://www.alegrar.com.br/04/textos_A_04/03_escrita.pdf>. Acesso em: 9 jun. 2015.

Data de recebimento: 10 de dezembro de 2016.

Data de aceite para publicação: 03 de maio de 2017. 